\title{
FRONTERAS ESTÉTICAS DE LA ANALOGÍA MEDIEVAL. DEL ADORNO RETÓRICO A LA BELLEZA DEL VERBO
}

\author{
José Aragüés Aldaz \\ Universidad de Zaragoza.
}

\section{RESUMEN}

La reflexión sobre la analogía y la semejanza invadió todos los ámbitos del pensamiento medieval. La retórica y la teología compartieron un léxico único, pero mostraron planteamientos bien diferentes en esa fundamentación estética de la sinilitudo. La retórica definió todas las formas de la comparación como medios para la elocutio del discurso. Los teólogos escolásticos, por el contrario, al amparo de la imperfecta analogía existente entre Dios y sus criaturas, descubrieron en el universo un medio para la reflexión acerca de la pulcritudo divina. La posibilidad evidente de una conciliación entre ambos planteamientos no fue aprovechada en el período medieval, con raras excepciones.

Palabras clave: Analogía, Escolasticismo, Estética, Retórica, Teología, Semejanza,

\section{ABSTRACT}

The reflection about analogy and simile invaded all the fields of the medieval thought. Rhetoric and Theology shared a unic terminology, but these disciplines showed different expositions concerning aesthetic basis of similitudo. Rhetoric defined all the forms of the simile like instruments for elocutio. On the contrary, the scholastic teologians, beginning with the analogy between God and his creatures, discovered in the universe the way for a reflection about the divine pulcritudo. The evident opportunity of a conciliation between these disciplines was not taken in the Middle Ages, with rare exceptions.

Key words: Analogy, Scholasticism, Aesthetic, Rhetoric, Theology, Simile.

Et sic patet, quomodo multiformis sapientia Dei, quae lucide traditur in sacra Scriptura, occultatur in omni cognitione et in omni natura. Patet etiam, quomodo omnes cognitiones famulantur theologiae; et ideo ipsa assumit exempla et utitur vocabulis pertinentibus ad onne genus cognitionis.

Los últimos renglones del opúsculo De reductione artium ad Theologiam ${ }^{1}$ iluminan y oscurecen, a un tiempo, los variados matices que el pensamiento analógico hubo de adoptar en todos los

1 De reductione artium ad theologiam, 26, en Obras de San Buenaventura. Edición bilingüe, tomo I, ed. de L. Amorós, B. Aperribay, M. Oromí y L. Villuendas Polo, Madrid, Biblioteca de Autores Cristianos, 1955, p. 667 («Así queda 
ámbitos de la escritura medieval. Apenas unas líneas más arriba, San Buenaventura había éstablecido un estricto sistema de semejanzas entre los usos y modos de cualquier actividad cognoscitiva - de la percepción del mundo sensible a la especulación filosófica-y tres de las ideas esenciales de la doxa cristiana: la condición de un Verbo «engendrado eternamente y encarnado en el tiempo», la unión del alma y Dios y la existencia de un ordo vivendi, expresado, a mayor abundamiento, de acuerdo con un sistema ternario de virtudes de indudable raigambre escolástica. Como la naturaleza, el conocimiento humano es también modesto reflejo y sutil alegoría de la sabiduría eterna, hermosa copia de un exemplar divino perfecto y preexistente. Una lectura teológica harto sugerente, es cierto, pero un tanto engañosa si de lo que se trata es de explicar, pongamos por caso, la modesta condición que el pensamiento analógico podía asumir desde la lejana orilla retórica. Figura para el adorno de un discurso elocuente e instrumento para un sermón destinado preferentemente ad docendos plebeos, la comparación oratoria sería testigo de una libertad imaginativa o de una ausencia de sistematismo en su formulación, si se prefiere- que no puede sino contrastar con el rigor y la perfección anunciados para las formas afines desde la más alta especulación metafísica. Existe una evidente distancia conceptual entre aquel ejemplarismo divino explorado por San Buenaventura y lo que, quizá con alguna inexactitud, pudieramos denominar literatura retórico-ejemplar. La filiación léxica entre esos dos ámbitos que parecen anunciar pasajes como el que abre estas páginas - una apelación a los exempla humanos que preludia la tardía alusión de Robert Basevorn a la utilidad en la prédica de los exempla in arte- delata, por encima de todo, lo engañoso de una terminología compartida por teólogos y oradores desde presupuestos tan sólo parcialmente afines. ${ }^{2}$

\section{NIHIL PROBAT}

Alrededor de voces como exemplum y similitudo —esta última tanto o más frecuente que aquella también en el discurso escolástico- había fundado la nueva prédica una teoría de la comparación argumentativa deudora, en buena medida, de las tesis grecolatinas al respecto. Poco hace al caso que esos mismos términos pudieran ostentar en las retóricas clásicas y medievales, de modo alternativo, valores equivalentes 0 contradictorios: ${ }^{3}$ su concurrencia en los textos fue siempre acom-

patente cómo la multiforme sabiduría de Dios, que con gran claridad se nos manifiesta en la Sagrada Escritura, se oculta en todo conocimiento y en toda naturaleza. Aparece, además, cómo todo conocimiento presta vasallaje a la Teología, por lo que ella toma los ejemplos y utiliza la terminología perteneciente a todos los géneros del conocimiento»).

2 Robert Basevorn aludía en su ars preadicandi a una triple modalidad analógica: exempla in arte, in natura, in historia. La segunda de esas modalidades apela, obviamente, a aquellos ejemplos naturales también recordados por San Buenaventura en el conjunto de su obra (cfr. infra). Para la exposición de Basevorn y otros testimonios afines, vid. Hauf, H.G., «El Ars Praedicandi de Fr. Alfonso d'Alprão, O.F.M. Aportación al estudio de la teoría de la predicación en la Península Ibérica», en Archivum Franciscanum Historicum, 72 (1979), pp. 233-329, p. 303.

3 La definición de términos como exemplum o similitudo planteó enormes problemas ya a los tratadistas clásicos. El sentido amplio de la voz exemplum - toda comparación retórica - fue expuesto por Quintiliano, y recordado en fechas bien tardías por Erasmo o Cavalcanti. También la voz similitudo ostentó ese sentido global en ocasiones. Ambos términos poseían sin embargo acepciones más específicas, y podían servir para la calificación de categorías individuales en el seno de la amplia comparación argumentativa. De acuerdo con ese sentido específico, precisamente, había de ser planteada su 
pañada de una oportuna reflexión sobre aquellas virtudes gnoseológicas - facilidad para la comprensión de las nociones abstractas, utilidad para la evocación casi visual de un complejo universo de vicios y virtudes, instrumento para la pronta rememoración de los pormenores de la via salutis- que habían de compartir símiles naturales, alegorías, apólogos, narraciones históricas y tantas otras formas dotadas - 0 susceptibles, al menos - de una lectura translaticia o metafórica: Exempla mentem efficacius movent, memoriae firmius haerent, intellectui facile lucent, delectant auditum, fovent affectum, removent taedium, vitam informant, mores instruunt, \& dum sua novitate sensum permulcent, odiosam praedicatori somnilentiam fugant. ${ }^{4} \mathrm{Es}$ bien conocido que la adecuación de esa literatura a las tres potencias del alma sería el origen de un aprecio oratorio sin apenas límites, pero quizá se haya insistido algo menos en los propios recelos que la dialéctica o la filosofía habían de mostrar ante lo que constituía un medio oblicuo (obliqua vestigia) para la comprensión de la verdad o, a lo sumo, un recurso accesorio para su exposición ante un público indocto o incapacitado para la abstracción. De la primera cautela serían testigo aquella sentencia agustiniana recordada todavía en el Seiscientos por Lorichius en su Thesaurus (sana ratio etiam exemplis anteponenda est), la más compleja reflexión de Paschalius en su extensa enciclopedia moral (nulli ergo prudenti exempla sunt pro ratione, exemplum nunquam ducit rationem... Ergo sola ratio est rei agendae regula. Nec ubi ratio desideratur exemplorum valere debet auctoritas) o la tajante opinión de Pablo José de Arriaga en torno a la ineficacia argumentativa de la semejanza (similitudo nihil probat) ${ }^{5}$; de la segunda, un abanico casi infinito de testimonios que, de Macrobio a Rodolfo Agrícola, ponderaban el valor de ejemplos y símiles para el adoctrinamiento de plebeia ingenia, homines rudiores animi y hebetes, en un planteamiento asumido incluso en la más copiosa colec-

oposición en los textos, en ocasiones ál amparo de la fórmula inter exemplum et similitudinem hoc interest... De este modo, hubo de insistirse en el valor narrativo del exemplum, frente a la consideración descriptiva de la similitudo (Quintiliano, Casiodoro, Ródrigo de Arriaga, Pelletier), al valor literal del primero y metafórico de esta última (Marius Servius Honoratus, Pedro Juan Núñez), o a su carácter histórico y ficticio, respectivamente (Nebrija, Petrus Mosellanus, Erasmo). Para una exposición más amplia, me permito remitir a mi estudio «Deus concionator». Mundo predicado y retórica del «exemplum» en los Siglos de Oro, Amsterdam, Rodopi, 1999, pp. 23-66.

4 Magnum Speculum Exemplorum, Douay, Baltasar Bellerus, 1614 [Zaragoza, Biblioteca Universitaria -en adelante, B.U.Z. - sign. G-28-101], Prologus, s.f. («Los ejemplos mueven de modo más eficaz el espíritu, se fijan más firmemente en la memoria, se hacen visibles con mayor facilidad para la mente, deleitan el oído, dan calor al afecto, disipan el tedio, enseñan para la vida, instruyen sobre las costumbres y, cuando con su novedad acarician el sentido, destierran al predicador la odiosa somnolencia»). Cfr. así mismo: Narraciones (...) et exempla facilius in intellectu capiuntur et memorie firmius imprimiuntur et a multis libencius audiuntur (Humbert de Romans, Liber eruditionis religiosorum, Praefatio, cit. por Welter, J.Th., L'exemplum dans la littérature religieuse et didactique du Moyen Age, París-Toulouse, 1927, p. 72; «Narraciones (...) y ejemplos se perciben mejor por la mente, se imprimen de modo más firme en la memoria y son escuchados por muchos con mayor agrado»).

5 La opinión de San Agustín (Ad Casulanum) es recogida por Dominicus Nanus Mirabellus, Bartholomeus Amantius y Franciscus Tortius, Polyanthea nova, Francfurt, Lazarus Zetznerus, 1607 [B.U.Z. G-58-1], sub voce 'exemplum' («La correcta razón ha de ser antepuesta a los ejemplos»). Iodochus Lorichius varía un tanto la formulación de la sentencia: Exempla non debent praevalere sanis rationibus (Thesaurus novus utriusque Theologiae Theoricae et Practicae, Friburgo, Martinus Bockler, 1609 [B.U.Z. G-76-22], pp. 984-985; «Los ejemplos no deben prevalecer sobre las razones correctas»). Y cfr., respectivamente, Carolus Paschalius, Virtutes et vitia, París, Eustachius Foucault, 1615 [B.U.Z. G-31-36], p. 241 («Los ejemplos no ocupan el lugar del razonamiento para nadie que sea prudente, el ejemplo no guía a la razón... Por lo tanto, sólo la razón es regla válida de lo que ha de ser hecho, y allí donde la razón se requiere no debe prevalecer la autoridad de los ejemplos»); Pablo José de Arriaga, Rhetor christianus, Lyon, Horatius Cardon, 1619 [G-36292], p. 285 («El símil no prueba nada»). 
ción de similitudines del Medioevo: una Summa como la de Ioannes de Sancto Geminiano dirigida, prioritariamente, al «vulgo y a los hombres más simples», ${ }^{6}$ Es cierto que en las palabras de su autor - sobre las que hemos de volver en estas páginas- hay algo de la tópica modestia prologal que diluye el cometido, algo más trascendente, de tan magna obra: el mundo sensible constituye el medio de acceso de todo hombre a las realidades intelectuales y el símil hubo de ser un eslabón ineludible, universal, en ese camino a visibilibus ad invisibilia reseñado por San Agustín o Santo Tomás a tantos propósitos ${ }^{7}$. Pero era precisamente la adecuación de las formas breves a un auditorio popular el garante de su éxito en un sermón sentido como digno heredero de la sencilla prédica de Cristo en la tierra. Un discurso este último tan breve y prudente, como diáfano (apertissimus) y fecundo en parábolas, al decir del autor de las Similitudines sive collationes ex Bibliis Sacris, Alardo de Amsterdam: Pectus instruximus, negleximus linguam, subtilia didicimus, familiaria fastidimus. Quod iis qui se popularibus functionibus destinarunt, minime faciendum esse indicio fuerit serva* tor ille noster Dominus Iesus Christus, in quo sunt omnes thesauri sapientiae ac scientiae reconditi, cuilus ut prudentissimi brevissimique fuere sermones, ita apertissimi atque parabolarum plenissimi. ${ }^{8}$

La equivalencia entre los conceptos de parábola evangélica y símil oratorio constituía, de hecho, un topos casi incontestable para los lectores tardíos de la colección de Alardo, y en esa identidad hubo de fundarse la dignidad de un género retórico-literario como el que nos ocupa, ofrecido por los autores cristianos como mero remedo de las formas ensayadas por un Cristo poeta. ${ }^{9} \mathrm{Ya}$ en

6 Para el pasaje de Macrobio (Saturtalia, 1), vid. Dominicus Nanus Mirabellus, loc.cit: Plebeia ingenia magis exemplis, quam oratione capiuntur ( $\alpha$ Las mentes sencillas son atraídas mejor con ejemplos que con un discurson). Según Rodolfo Agricola: Copiosi sunt hi duo loci (exempla et similitudines), et vulgi opinioni sensibusque aptissini. Nan ut comparatis facile pervincuntur rudiores animi (non enim facilius quisquam credit, quan quo iam in alio videtur probasse) sic similitudo ad explanandum est iisdem maxime accommodata (De inventione dialectica, París, Guillelmus Richardus, 1542 [B.U.Z. G-12-132], pp. 58-59; «Fecundos son estos dos lugares, ejemplos y síniles, y muy aptos para la opinión y los sentidos del vulgo. Pues, del mismo modo que por medio de las comparaciones se convencen los espíritus más nudos (nada cree más fácilmente cualquiera que aquello que parece estar probado en atro), asi è símil es lo más apropiado para explicar algo a los mismosm). El pasaje de Ioannes de Sancto Geminiano en Universum praedicabile (Summa de exemplis et similitudinibus), Colonia, Ioannes Amoldus Cholinus, 1670 [B.U.Z. G-26-58], p. 2. Y cf., entre tantos otros testimonios, Juan Luis Vives, De ratione dicendi, en Opera Omnia, Valencia, Benedicto Monfort, 1782 [B.U.Z. G-66-221]. III, p. 196; Lorenzo de Villavicencio, De formandis sacris concionibus, I, XX, Amberes, Vidua \& Haeredes loannis Stelsii, 1565 [Madrid, Biblioteca Nacional -en adelante, B.N.M - sign. R-31643], pp. 115-116; Laurentius Beyerlinck, Magnum Theatrum Vitae Humanae, Lyon, Ioannes Antonius Huguetan, 1678 [B.U.Z. G-80-10], p. 9.

7 Son palabras de San Agustin (Epistolae, en Migne, PL, LV, p. 211; «De las cosas visibles a las invisibles, de las corporeas a las espirituales, de las temporales a las ctemasm). Y cfr. el testimonio de Santo Tomás de Aquino: Est autem naturale homini ut per sensibilia ad intelligibilia veniat: quia omnis nostra cognitio a sensu initum habet (Summa. Theologica, I, I, Madrid, Biblioteca de Autores Cristianos, 1947, p. 9; «Es innato al hombre que acceda a las cuestiones intelectuales a través de lo sensible, ya que todo nuestro conocimiento tiene su inicio en el sentidon). Para los pormenores de esa actividad intelectiva, vid. Ercilla, J, de, De la imagen a la idea. Estudio crítico del pensamiento tomista, Madrid, Gredos, 1959.

8 Lyon, s.i., 1543 [B.U.Z. H-24-89], Ad Lectorem, s.f. («Hemos instruido nuestra mente, hemos descuidado nuestra lengua, aprendimos cosas sutiles, despreciamos las familiares. De que no deben hacer esto los destinados a una misión popular es prueba el Salvador, Nuestro Señor Jesucristo, que posee todos los tesoros escondidos de la sabiduría y de la ciencia, y cuyos sermones fueron tan prudentes y breves, como elocuentes y plagados de parábolasy).

9 Ya Quintiliano había indicado la sinonimia entre el término parabola y el latino similitudo (vid. Institutio oratoria, V, 11, 23, ed. de J. Cousin, París, Les Belles Lettres, V, p. 169). Para la asimilación de la parábola evangélica a la definición retórica de similitudo, cfr, en efecto, las palabras de Alardo de Amsterdam (o.c., fol. 135r): Parabola in scrip- 
el ámbito hispánico, y en fechas próximas, Juan Granada desbordaría incluso esa reflexión sobre los modos narrativos del Evangelio para anunciar la vocación analógica de todo el texto bíblico (omnia fere scripturae sacrae volumina). Y lo haría de nuevo a partir de una conciliación sacro-profana -enunciada desde el recuerdo de una media docena de gravissimi philosophi- que demostraba la pertinencia de la imaginación alegórica en todos los ámbitos elocutivos:

Hinc fit ut intellectus etiam cum gravi corporis sarcina praemitur, figuratis locutionibus, \& mutuatis a rebus corporalibus imaginibus delectetur: nec delectatur solum, sed ad res difficiles intelligendum magnopere adiwatur: fit enim multoties, quae difficilia alias iudicantur, ab intellectu, proposita similitudine percipi. Propterea Philosophorum gravissimi Pythagoras, Demophon, Diogenes, Plato, Aristoteles, Theophastrus maximan \& praestantiorem philosophiae partem, parabolis condiderunt. Sed ut prophanos onittamus, omnia fere scripturae sacrae volumina, intermixtis methaphoris scatere videntur ${ }^{10}$

\section{TALIBUS SIMILITUDINIBUS UTITUR}

No deja de resultar curioso, por todo ello, que también San Buenaventura pudiera apelar, desde su particular concepción de la analogía teológica, a esa vocación metafórica del texto sagrado, ofreciendo una filiación con las doctrinas oratorias que su propio discurso había de atenuar algo más adelante: Ecce, quomodo illuminatio artis mechanicae via est ad illuminationem sacrae Scripturae, et nihil est in ea, quod non praedicet veram sapientian. Et ideo sacra Scriptura frequenter talibus sinilitudinibus utitur satis recte." Desde el referente de las Sagradas Letras, en efecto, podía ser impulsada la lectura de la Creación y del propio hombre como reflejo de Dios, idea fácilmente asimilada a una interpretación del cosmos de raigambre platónica. El neoplatonismo cristiano sería así el sustento de un edificio teológico alzado desde los escritos de San Agustín, el Pseudo Dionisio, Juan Escoto Eriúgena, San Buenaventura y Santo Tomás, y que había de aunar cuantas reflexiones sobre tan suprema alegoría había desplegado la propia literatura hexaemeral, desde los textos fun-

turis sacris est diversarum rerun collatio seu comparatio, sic vocata, quod una res est alteri aut assimilata, aut compa* rata, quasi praevia veritatis umbra Quod enim parabola Graeco vocabulo appellatur, hoc Latine similitudo dicitur («Parábola, en las Sagradas Escrituras, es una confrontación o una comparación entre cosas diversas, así llamada porque una cosa es asimilada o comparada a otra, por así decirlo, con una previa apariencia de verdad. Aquello, así pues, que se denota con la palabra griega 'parábola', se llama en latín 'simil's). La confrontación entre la parabola retórica y la evangélica ofrece, sin embargo, numerosos matices, que no es posible abordar aquí. Analizo la cuestión en mi o.c., pp. 43-47.

10 Juan Granada, Parabolae evangelicae, Zaragoza, Lorenzo y Diego Robles, 1585 [B.U.Z. H-9-77], p. 1 («De aquí sé sigue que el intelecto, incluso cuando esté apremiado por una pesada carga, se deleite con palabras figuradas e imágenes tomadas de las cosas corporales. $Y$ no sólo se deleita, sino que es ayudado a comprender crestiones en extremo dificiles. Así pues, muchas veces se consigue que sean percibidas por la inteligencia, por medio de un símil propuesto, aquellas cosas que eran tenidas por complicadas. Por esta causa, los filósofos más profundos, Pitágoras, Demofonte, Diógenes, Platón, Aristóteles o Teofrasto, fundaron en parábolas la parte de la filosofía más alta y principal. Pero, dejando a un lado los profanos, casi todos los libros de la Sagrada Escritura parecen estar llenos de metáforas entremezcladas»).

11 O.c., p. 658 («He ahí cómo la iluminación del arte mecánica es recto camino hacia la iluminación de la Sagrada Escritura, y nada puede en ella encontrarse que no esté de continuo predicando la verdadera sabiduría. Por esto la Sagrada Escritura frecuentemente se sirve de tales semejanzas con mucha propiedads). 
dadores de San Basilio y San Ambrosio: la evidencia de una Creación sentida como incesante suma de teofanías, la consideración del mundo como libro plagado de «imágenes simbólicas» o la percepción de un universo armónico dictado por la voluntad artística de su Creador. ${ }^{12}$

La distancia de tales planteamientos con respecto a los que informaban las tesis oratorias sobre la metáfora cobra así una dimensión definitiva ante esa creencia teológica en la analogía como principio que informa la esencia de todo lo creado. $Y$ a ese proceso de deslinde entre ambas disciplinas, entre ambos modos de pensamiento, apunta sin lugar a dudas el propio empleo de un término como similitudo en la obra de San Buenaventura. La idea de que el hombre sólo puede acceder a la realidad por medio de semejanzas, expresada en sus comentarios a las Sententiae de Pedro Lombardo, constituye de hecho una mera reflexión sobre el carácter virtual del pensamiento y el lenguaje humanos y no, desde luego, una indagación sobre las virtudes cognoscitivas del discurso metafórico, como era cuestión en los preceptistas oratorios. Y cuando esa indagación aparece en la obra del franciscano, lo hace teñida de una trascendencia bien distante de la manifestada por estos últimos. Es cierto que la idea de que todo el universo reproduce a Dios resulta fácilmente conciliable con las tesis retórico-ejemplares hasta aquí planteadas, pero la tentación del uso de una voz como similitudo para definir esa relación analógica queda pronto superada por los rigores de una terminología escolástica que se quiere mucho más precisa:

Omnis enin creatura ex natura est illius aeternae sapientiae quaedam effigies et similitudo, sed specialiter illa quae in libro Scripturae per spiritum prophetiae assunta est ad spiritualium praefigurationem; specialius autem illae creaturae, in quarum effigie Deus angelico ministerio voluit apparere; specialissine vero ea quam voluit ad significandum instituere, quae tenet non solum rationem signi secundum nomen commune, verum etiam Sacramenti. ${ }^{13}$

12 Para una primera aproximación a las tesis esenciales de ese ejemplarismò divino, vid. Guelluy, R., La Creación, trad. de D. Ruiz Bueno, Barcelona, Herder, 1979; Auer, J., El nutundo, creación de Dios, trad, de C. Gancho, en J. Auer y J. Ratzinger, Curso de Teología Dogmática, Barcelona, Herder, 1979, vol. III; y el sugerente y amplísimo estudio de Von Balthasar, H.U., Gloria. Una estética teológica, trad. de J. L. Albizu, Madrid, Ediciones Encuentro, 1986, esp. tomos II y IV. Cfr. así mismo la bibliografía citada en Johnston, M.D. (ed.), Ramon Llull's New Rhetoric. Text and Translation of Llull's «Rethorica Nova», Davis, Hermagoras Press, 1994, esp. notas 26 y 44. De especial interés resultan, al propósito que nos ocupa, los estudios de Day, S.J., Intuitive Cognition. A Key to the Signifiance of the later Scholastics, Nueva York, St. Bonaventure, 1947; Javelet, R., Image et ressemblance au douzième siècle de Saint Anselme à Alain de Lille, Estrasburgo, Univ. de Strasbourg, 1967; Spitzer, L., L'armonia del mondo. Storia semantica di un'idea, Bolonia, Il Mulino, 1967; Papin, J., «Aspects théoriques du symbolisme dans la tradition dionysienne; antécedents et noveautés», en Simboli e simbologia nell'alto medioevo, Spoleto, Centro Italiano di Studi sull'Alto Medioevo, 1976, pp. 33-79; Gersh, S., From Iamblichus to Eriugena: An Investigation of the Prehistory and Evolution of the Pseudo-Dionysian Tradition, Leyden, E.J. Brill, 1978; Illanes, J.L., «Fe y comprensión del mundo en la doctrina de Duns Escoto», en C. Berubé, (ed.), Homo et mundus, Roma, Societas Internationalis Scotistica («Studia Scholastico-Scotistica», 8), 1984, pp. 93-109. Para la evolución posterior de la lectura alegórica del cosmos en las letras europeas, vid. Lewis, C. S., La imagen del mundo, Barcelona, Bosch, 1980, pp: 69-91; y Gombrecht, E.H., Imágenes simbólicas, trad. de R. Gómez Díaz, Madrid, Alianza Editorial, 1983, pp. 233-263. El simbolismo animal a la luz de dicha concepción es analizado por S. Sebastián, Mensaje Simbólico del Arte Medieval. Arquitectura, Liturgia e Iconografia, Madrid, Ediciones Encuentro, 1984, pp. 245-270, con abundante bibliografía. Analizo algunos testimonios de la pervivencia de tales ideas en las letras de nuestro Siglo de Oro en mi o.c., pp. $77-81$.

13 Itinerarium mentis in Deum, II, 12, en Obras de San Buenaventura, I, o.c., pp. 588-589 («Y es que toda criatura, por su naturaleza, es como una efigie o similitud de la eterna sabiduría; pero lo es especialmente aquella que, en la 
La elocuente gradación de afinidades entre el sentido recto del término y las realidades denotadas con mayor propiedad por el mismo (sed specialiter illa... specialius autem illae... specialissime vero ea...) manifiesta esa concepción jerárquica de una realidad multiforme, y es solidaria con la distinción bonaventuriana entre los meros vestigia de Dios, sus imagines y sus estrictas similitudines, es decir, entre las operaciones naturales, las espirituales y las meritorias: in creaturis reperitur triplex modus conformitatis ad Deum. Quaedam enim conformantur Deo sicut vestigium, quaedam sicut imago, quaedam sicut similitudo. ${ }^{14}$ Pero la voz tampoco agotaría allí su elenco de significados, porque es el Verbo engendrado la imago Dei y su auténtica semejanza (similitudo, de nuevo), de acuerdo con ese lugar central que el pensamiento bonaventuriano otorgó a un Cristo constituido en llave de la contemplación divina y de la recta interpretación del libro de las criaturas. Y también el Hijo de Dios se identifica, esta vez con un criterio descendente, con el arte divino y el arquetipo único de la Creación, con el modelo ejemplar de todo el universo. ${ }^{15}$ Una profusión de ideas analógicas que, en definitiva, ya había llevado a San Anselmo a precisar el engañoso sentido de la voz similitudo en su aplicación a las ideas ejemplares contenidas en el Verbo, dadas las connotaciones de ese tecnicismo en el ámbito de los estudios sobre el lenguaje humano. La vir-

Sagrada Escritura, se tomó, por espíritu de profecía, para prefigurar las cosas espirituales; más especialmente aquellas criaturas en cuya figura quiso Dios aparecer por ministerio de los ángeles y, especialísimamente, por fin, aquella que quiso fuese instituida para significar, la cual no sólo tiene razón de signo común, sino también de signo sacramental»). Para la limitación del conocimiento humano a la percepción de las semejanzas, vid. la Introducción general de L. Amorós en Ibíd., especialmente, pp. 122-123 (donde se remite a San Buenaventura, I Sent, d. 35, art. un., qu. I). Amorós ofrece un análisis detenido de la obra y la filosofía de San Buenaventura (añádase la Bibliografía recogida en el mismo volumen, esp. pp. XLII-XLVIII). Un panorama muy sugerente del conflicto entre aristotelismo y platonismo a la luz de ese planteamiento ofrece Fr. Miguel Oromí, «Filosofía ejemplarista de San Buenaventura», en Obras de San Buenaventura, tomo III, ed. de L. Amorós, B. Aperribay y M. Oromí, Madrid, Biblioteca de Autores Cristianos, 1957, pp. 3-138. Y vid. Bissen, J.M., L'exemplarisme divin selon Saint Bonaventure, París, 1929; Gilson, E., La filosofia de San Buenaventura (1929), trad. esp. en Buenos Aires, 1948; Van de Woestyne, Z., «Augustinismus in gnoseologia S. Bonaventurae et S. Thomae», en Antonianum, VIII (1933), pp. 281-306, y IX (1934), pp. 383-404 y 475-504; Picard, N., «Gnoseologia Bonaventuriana?», en Antonianum, XVII (1943), pp. 217-244; y Von Balthasar, H.U., o.c., II, pp. 253-342.

14 Christus, unus omnium magister, 15, en Obras, I, 0.c., pp. 690-691 («En las criaturas se dan tres maneras de conformidad con Dios. Algunas se conforman con Dios como vestigio, otras como imagen, otras como semejanza»). Y cfr.: In illis, ergo operationibus creaturae, quae sunt ipsius, in quantum est vestigium, sicut sunt universaliter actiones naturales, cooperatur Deus sicut principium et causam. In his autem, quae sunt ipsius, in quantum est imago, sicut sunt actiones intellectuales, quibus anima percipit ipsam veritatem immutabilem, cooperatur sicut obiectum et ratio motiva. In his vero, quae sunt ipsius in quantum est similitudo, sicut sunt operationes meritoriae, cooperatur sicut donum infusum per gratiam (Ibid., pp. 692-693; «En aquellas operaciones de la criatura que le son propias como vestigio, como son en general las acciones naturales, Dios coopera como principio y causa. Mas en aquellas que le son propias en cuanto imagen, como son las operaciones intelectuales con las cuales el alma percibe la verdad inmutable, coopera como objeto y razón motriz. Y en aquellas que le son propias en cuanto semejanza, como son las operaciones meritorias, coopera como por don infuso por la gracias).

15 Para el papel del Verbo como imago Dei y ejemplar de todo lo creado, cfr. vgr. Collationes in Hexaëmeron, coll. I, 13, en Obras, III, o.c., pp. 184-187: Pater enim ab aeterno genuit Filium similem sibi et cum hoc totum posse suum; dixit quae posset facere, et maxime quae voluit facere, et omnia in eo expressis, scilicet in Filio seu in isto medio tanquam in sua arte («Porque el Padre engendró desde la eternidad al Hijo semejante a sí y se dijo a sí mismo y dijo su similitud semejante a sí, y con ello todo su poder; dijo las cosas que podría hacer, y máxime las que quiso hacer, y las expresó todas en él, esto es, en el Hijo o en este medio, como en su arte», ). Y vid. Breviloquium, I, III, 8, en Obras, I, o.c., p. 213. Para el sentido de términos como idea, arte o razón aplicados a la divinidad, vid. Ibíd., I, VIII, pp. 231 y ss. Consúltese así mismo Von Balthasar, H.U., o.c., II, esp. pp. 275-318 y 334-342. 
tualidad -y posterioridad - de toda semejanza verbal con respecto a la realidad denotada condecía bien poco con la dirección de una actividad creadora en la que la similitudo divina era, obviamente, anterior e infinitamente más real que todo ser creado:

Satis itaque manifestum est in verbo, per quod facta sunt omnia, non esse ipsorum sinilitudinem, sed veram simplicem essentiam; in factis vero non esse simplicen absolutamque essentian, sed verae illius essentiae vix aliquam imitationem. Unde necesse est non idem verbum secundum rerum creatarum similitudinem magis vel minus esse verum, sed omnem creatam naturam eo altiori grado essentiae dignitatisque consistere, quo magis illi propinquere videtur: ${ }^{16}$

Ideas como la de la falsedad del mundo natural o sensible («toda criatura es mentira», según declaraba San Agustín y recordaba el propio San Buenaventura) conducían así el discurso teológico, al amparo de una voluntad de indagación ontológica harto más ambiciosa que la evidenciada por la oratoria. ${ }^{17}$ Ahora no se trataba ya de hallar un modus intelligendi eficaz y proporcionado a las necesidades del auditorio popular, sino de dar cuenta de un modus essendi sustancialmente analógico por voluntad divina. Tanto como fin al que se accede por la contemplación de las criaturas, Dios es origen, principio y ejemplar de su esencia - quia Deus est ommis creaturae origo, exemplar et finis, et omnis effectus est signum causae, et exemplatum exemplaris, et via finis, ad quem ducit $^{18}$-, y a esa luz han de entenderse las nuevas matizaciones léxicas que el propio San Buenaventura deslizaba, una y otra vez, en su copiosa obra. El oportuno reconocimiento de esa doble condición de unos entes naturales sentidos a un tiempo como exemplaria -modelos para su consideración por parte del hombre-y exemplata o copias del original divino, y la sutil inclinación hacia esa última lectura que manifiesta el Itinerarium mentis in Deum - quae, inquam, sunt exemplaria vel potius exemplata, proposita mentibus - constituyen el mejor resumen de la voluntad ontológica de su discurso; un discurso que, de nuevo al hilo de una comparación lingüística, hacía de la criatura signum y de Dios significatum previo y real, en perfecto acuerdo con las tesis más rigurosas recién recordadas para la obra de San Anselmo. ${ }^{19}$ :

16 Monologium, XXXI, en Obras completas de San Anseimo, intr., trad. y notas de J. Alameda, Madrid, Biblioteca de Autores Cristianos, 1952, pp. 272-273 («Así queda suficientemente demostrado que no hay en el Verbo, que ha hecho todas las cosas, ninguna semejanza de las mismas, sino una esencia verdadera y simple; que, al contrario, en las cosas creadas no hay esencia simple y absoluta, sino apenas una imitacion lejana de esta verdadera escncia. De donde se sigue necesariamente que este Verbo no es más o menos verdadero según su semejanza con las cosas creadas, sino que las cosas creadas ocupan un lugar tanto más alto y son de una esencia tanto más digna, cuanto más se acercan a este Verbo»).

17 Ideo onnis creatura mendacium esi, secundum Augustinum (...) Verbum vel similitudo vel ratio sit veritas; et ibi est veritas creatura, et repraesentantur per Verbum ita infima sicut suprema (Collationes in Hexaëmeron, coll. III, 8, o.c., pp. 236-237; «Según San Agustín, toda criatura es mentira... Luego es necesario que el Verbo o la semejanza o la razón sea la verdad; y en el Verbo está la verdad de la criatura, y por el Verbo son representadas tanto las cosas ínfimas como las supremas»).

18 Itinerarium mentis in Deum, II, 12; 0.c., pp. 588-589 («Porque Dios es el origen, el ejemplar y el fin de las cosas creadas y porque todo efecto es signo de la causa, toda copia lo es del ejemplar, todo camino lo es del fin al que conducen»).

19 Omnes creaturae istius sensibilis mundi (...) sunt vestigia et simulacra et spectacula nobis ad contuendum Deum proposita et digna divinitus data; quae, inquan, sunt exenplaria vel potius exemplata, proposita mentibus adhuc nudibus et sensibilibus, ut per sensibilia, quae vident transferantur ad intelligibilia, quae non vident, tanquam per signa ad signa- 
El propio tono de los pasajes citados ofrece, incluso, un enésimo motivo para la reflexión sobre esa distancia entre los planteamientos teológicos y oratorios. Frente a la predilección de estos últimos por los símiles deducidos del mundo natural - que explica la constante inserción de materiales procedentes de bestiarios y lapidarios en las colecciones al servicio del predicador-, San Buenaventura parece hallar sus argumentos metafóricos en los usos y modos en que ese mundo es percibido por la mente del hombre. Y es esa «querencia cognoscitiva», ese interés por la lectura metafórica del lenguaje y el pensamiento humanos, la que impregna todos sus escritos. La idea, presente en el Itinerarium, de que las scriaturas de este mundo sensible significan las perfecciones invisibles de Dios», expresada al amparo del pasaje paulino y perfectamente conciliable con las tesis oratorias al respecto, adquiere en efecto un tono mucho más específico a la luz de los primeros epígrafes de esa misma obra. ${ }^{20} \mathrm{Si}$ es cierto que el primer capítulo muestra un primer grado de acceso a la divinidad un tanto convencional - la elevación del alma a la consideración de la «potencia, la sabiduría y la bondad de Dios como existente, viviente e inteligente, puramente espiritual, incorruptible e inmutable», no lo es menos que esa primera vía en el speculationum progressus indaga ya la existencia de tres modos de apreciación mental (el entendimiento que contempla, el que cree y el que investiga racionalmente) ${ }^{21}$ y que esa imagen cognoscitiva - hasta aquí mero modo de organización del discurso, si se quiere - acaba por convertirse, en el segundo epígrafe, en la propia materia analógica, en el objeto contemplado para el ascenso metafórico a Dios, vinculando al

ta (Ibíd. II, 11, pp. 588-589; tTodas las criaturas de este mundo sensible... son no solamente vestigios, simulacros y espectáculos puestos ante nosotros para cointuir a Dios, sino también signos que, de modo divino, se nos han dado; son, en una palabra, ejemplares 0 , por mejor decir, copias propuestas a las almas todavía rudas y materiales para que de las cosas sen. sibles que ven se trasladen a las cosas inteligibles como del signo a lo significadow). El término exemplar hacía referencia al objeto digno de imitación; la vơz exentulum, al contenido de ese proceso mimético. Víd. San Buenaventura, I Sent, d. 31, p. 2, art. I, qu. I. Y cfr., Exemplum proprie dicitur quod sumitur ex aliquo, \& exemplar ex quo sumitur aliquid (Pedro Lombardo, Sententiarm Ibri quatuor, II, XVII, Amberes, Marcus \& Michael Bousquet, 1767 [B.U.Z. G-11-103], p. 224; « Se llama propiamente ejemplo aquello que se toma de algo, y ejemplar, aquello de donde se tomas). La distinción entre ambas voces era un lugar común. Cfr. vgr. las palabras de Festo, recogidas por Lorenzo Valla (Elegantaram latinae lin. guae libri sex, Lyon, Antonius Vicentius, 1545 [B.U.Z. H-24-150], sub voce 'exemplum'): Exemplum est quod sequamu' att vitemus; exemplar, ex quo sinile faciamtis. Illud animo aestimatu; istud oculis conscipitur (kjemplo es lo que debemos seguir o evitar, ejemplar, aquello a partir de lo cual hacemos una copia. Aquel se aprecia con la mente, éste se ve con los ojoss). Una postura más escéptica presenta Erasno al respecto en su Paraphrasis in Elegantiarum libros Laurentii Vallae, Lyon, S. Gryphius, 1533 [B.U.Z. H-3-143], sub voce 'exemplum': Exemplunt et exemplar pene nihil differunt. Exemplum, est res quam imitamur in aliquo, exemplar ex quo sumimus quod imitemur: illud contentum, hoc continens, sed confunditur differentia, si tamen est differentia («Ejemplo y ejemplar apenas se diferencian en algo. Ejemplo es aquello que imitamos de alguien, ejemplar, aquel del que deducimos lo que imitamos. Aquel es contenido, éste, continente. Pero se confunden sus límites, sì es que los hays).

20 Vid. Itinerarium mentis in Deum, II, 12; 0.c., pp. $588-589$. Y cfr. Rom, 1, 20.

21 Ex his ergo visibilibus consurgit ad considerandum Dei potentiam, sapientian et bonitatem ut entem, viventent

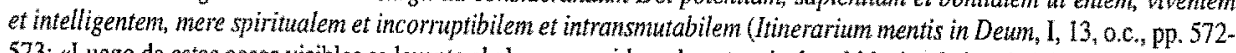
573; «Luego de estas cosas visibles se levanta el alma a considerar la potencia, la sabiduría y la bondad de Dios como existente, viviente e intcligente, puramente espiritual, incorruptible e inmutable). Y cfr. 1 bid., 1,10, pp. $570-571$ : Relucet autem Creatoris summa potentia et sapientia et benevolentia in rebus creatis, secundum quod hoc tripliciter nuntiat sensus carnis sensu interion. Sensus enim cants aut deservit intellectui rationabiliter investigant, aut fideliter credenti, aut intellectualiter contemplanti ( $Y$ en verdad reluce en las cosas creadas la suma potencia, la suma sabiduría y la suma benevolencia del Creador, conforme lo anuncia el sentido de la carne al sentido interior por tres modos. El sentido de la came, en efecto, sirve al entendimiento que investiga racionalmente, o al que cree fimemente, o al que contempla intelectualmentes). 
paso todos los matices apuntados para la voz similitudo; todo objeto genera de sí una semejanza, perceptible por los sentidos y el pensamiento humanos, simbolizando la eterna generación del Verbo, «imagen e Hijo que del Dios Padre emana etemamente», y su encarnación salvífica:

Et quod ille qui est imago invisibilis Dei et splendor gloriae et figura substantiae eius, qui ubique est per primam sui generationem, sicut obiectum in toto medio suam generat similitudinem, per gratian unionis unitur, sicut species corporali organo, individuo rationalis naturae, ut per illam unionem nos reduceret ad Patrem sicut ad fontale principium et obiectum $^{22}$.

De igual modo, el deleite en el conocimiento o la actividad del juicio humano en el descubrimiento de las verdades inmutables anuncia la procedencia de unas ideas que kexisten etemalmente en el arte eterna», ${ }^{23}$ con lo que cobran todo su sentido los capítulos últimos del Itinerarium - centrados en la consideración de la mente y el alma fortalecida por la gracia como depositarias de la verdadera imago et similitudo del Verbo ${ }^{24}$ - y ese pasaje que abría estas páginas: sutil superación del viejo tópico sobre el carácter ancilar de las ciencias, porque los modos del saber humano, en efecto, no son sólo medio propedéutico para el acceso a las cualidades divinas sino, quizá ante todo, sutil metáfora de las mismas. Tal condición ostentan la filosofía - racional, natural y moral-, el conocimiento sensitivo y unas artes mecánicas cuya explicación desliza incluso un par de mínimas consideraciones sobre la función del teatro y sobre el sentido del precepto horaciano del prodesse aut delectare. $^{25}$

22 Ibid, II, 7, pp. 582-583. El pasaje que precedía de modo inmediato al fragmento citado exploraba esa idea de generación en el conocimiento humano y en la acción divina: Nam cum species apprehensa sit similitudo in medio genita ef deinde ipsi organo impressa et per illam impresionem in sum principiun, scilicet in obiectum cognoscendum, ducat; manifeste insinuat, quod illa iut aeterna generat ex se similitudinem seu splendorem coaequalem, consubstantialem et coaeternalem. Tras la exposición reproducida en la cita, San Buenaventura ofrecia una suerte de resumen de la misma idea: Si ergo omnia cognoscibilia habent sui speciem generare manifeste proclamant, quod in illis tanquam in speculis videri potest aeterna generatio Verbi, Imaginis et Filil a Deo Patre aeternaliter emanantis («Porque siendo la especie que se aprehende semejanza engendrada en el medio e impresa desputós en el órgano, y llevándonos, en virtud de la impresión, al principio de donde nace, es decir, al conocimiento del objeto, nos da a entender de modo manifiesto no sólo que aquella luz eterna engendra de sí una semejanza o esplendor que es imagen del Dios invisible, esplendor de su gloria y figura de su substancia, sino también que aquel que es imagen del Dios invisible, esplendor de su gloria y figura de su substancia, existente en todas partes por su generación primera -el objeto engendra su semejanza en todo medio-, se une por la gracia de la unión - la especie se une al órgano corporal- a un indiviơuo de la naturaleza racional para reducimos mediante tal unión al Padre como a fontal principio y objeto. Luego todas las cosas cognoscibles, teniendo como tienen la virtud de engendrar la especie de sí mismas, prociaman con claridad que en ellas, como en espejos, puede verse la generación eterna del Verbo, Imagen e Hijo que del Dios Padre emana eternamenten).

23 Para esa lectura metafórica del deleite contemplativo, vid. infra. En lo que respecta al juicio: Si ergo onnia, quaecumque cersius diiudicamus, per huiusmodi rationem diiudicamus; patet quod ipse est ratio omnium rerum et regula infallibilis et lux veritatis (Ibid., II, 9, pp. 584-585; «Si cuantas cosas ciertamente juzgamos, por esas razones las juzgamos, cosa manifiesta es que Dios viene a resuitar la razón de todas las cosas y la regla infalible y la luz de la verdad»).

24 Para esa diferencia entre el Verbo como imago Dei y el hombre como ser creado ad imaginem et similitudinem de Dios, vid Von Balthasar, H. U., o.c., II, pp. 291 y ss.

25 Cfr. De reductione artium ad Theologiam, 2, 0.c., pp. 643-647. 


\section{PULCRITUDO}

Desde la tradición teológica $-\mathrm{y}$ no menos desde la retórica- habían de explorarse, por lo demás, las posibilidades estéticas de una analogía sustentada en un léxico de indudables connotaciones artísticas. La proliferación en los textos religiosos de voces como imago, similitudo, exemplum o exemplar era el origen - y el resultado, en más de una ocasión- de un constante recurso a los usos de la copia pictórica para la explicación de los pormenores de ese modo de pensamiento. Imagen doblemente plástica que contribuía por igual a afirmar una idea medular en el seno de la escritura escolástica - la voluntad artística del Creador, Deus artifex, en el despliegue armónico de sus semejanzas - y un tópico algo menos trascendente en el de la reflexión sobre la palabra oratoria: el de la proximidad entre los procedimientos de la mímesis pictórica y los de un aprendizaje de la virtud basado en la copia o imitación de los símiles y paradigmas morales. La explicación teológica del sintagma imago Dei abordada por San Agustín y Pedro Lombardo a partir de una mínima reflexión sobre el sentido de voces como tabula o pictura, o la más significativa referencia de San Buenaventura a las criaturas como sombras, vestigios o retratos de un ejemplar artístico preexistente - artis efficientis, exemplantis et ordinantis sunt umbrae, resonantiae et picturae- ${ }^{26}$ hallarían así su correlato en las precisiones de San Basilio o San Juan Crisóstomo sobre la necesaria contemplación interior (assidua contemplatio) de unas vitae sanctorum sentidas como muestra y modelo (exempla y exemplaria) para la mímesis ética, en un elemental juego de filiaciones estético-morales del que habría de hacerse eco, desde presupuestos algo más complejos, toda la escritura retórica de la Baja Edad Media. Para un Ioannes de Sancto Geminiano que parece remitir aquí a esa última tradición, el mundo de las criaturas -ese Universum praedicabile al que hacía referencia la obra desde su título - es ante todo exemplum y exemplar accesorio para un cristiano que dispone en su interior de un más acabado modelo artístico, la vida de Cristo:

Sed quemadmodum in operibus artiun, sic etian in moribus, \& actibus virtutum duplex habemus exemplun. Nam primo quidem per fidem habemus intus Christum. (...) Et hoc est exemplar praecipumn perfectae vitae. (...) Sed est aliud exemplar extrinsecum, scilicet natura creatarum rerum quae sunt extra animam, quod dinigitur humana industria, non tantum in operibus artium, (...) sed etiam in moribus, \& actibus virtutum (...) Nam ex ipsis

26 Vid. Pedro Lombardo, Sententiae, II, XVII, O.c., p. 225: Ita \& sectmdun animam dicitur homo esse inago Dei, quia imago Dei in eo est. Sicu inago dicitur \& tabula, \& pictura quat in ea est, sed propter picturam quae in ea est, simul \& tabula \& imago appellatur; ita propter imaginem Trinitatis illud in quo est imago, nomine imaginis vocatur ("Así, en relación con el alma se dice que el hombre es imagen de Dios, puesto que la imagen de Dios está en él. Como se llama imagen al cuadro y la pintura que hay en él, pero, a causa de esa pintura, del mismo modo se llama cuadro e imagen; así, por la imagen de la Trinidad, aquello en lo que está la imagen recibe el nombre de imagen»). Pedro Lombardo remite a San Agustín, De trinitate, XV, 2. La reflexión de San Buenaventura en Itinerarim, II, 11, o.c, pp. 586-588: Omnes creaturae istius sensibilis mundi animum contemplantis et sapientis ducunt in Deum aeternum, pro eo quod illius primi principii potentissimi, sapientissmi et optimi, illus aetemae originis, lucis et plenitudinis, illius, inquam, artis efficientis, exemplantis et ordinantis sunt umbrae, resonantiae ef picturae, sunt vestigia, simulacra et spectacula nobis ad contuendun Deum proposita et signa dininitus data («Todas las criaturas de este mundo sensible llevan al Dios Eterno al espiritu del que contempla y degusta, por cuanto son sombras, resonancias y pinturas de aquel Primer Principio, poderosísimo, sapientisimo y óptimo, de aquel origen, luz y plenitud eterna y de aquella arte eficiente, ejemplante y ordenante; son vestigios, simulacros y espectáculos puestos ante nosotros para cointuir a Dios»). 
naturae operibus, sumuntur similitudines \& plurima exempla utilia nostris competentia moribus. ${ }^{27}$

Pero la aparente homogeneidad terminológica y conceptual que presentan pasajes como los hasta aquí citados oculta de nuevo esa distancia que teólogos y oradores manifestaron en la fundamentación estética de la semejanza. El mencionado recuerdo oratorio de las facultades del ejemplo y el símil para Ia delectatio - exempla delectant auditum, exempla a multis libencius audiuntur ${ }^{28}$ - era afín a su inclusión en el elenco de figuras adecuadas para el adomo del discurso, en una lectura auspiciada, con idéntica convicción, por las disciplinas de la palabra clásicas y medievales. Es cierto que la idea de una similitudo que era a su vez forma argumentativa y figura elocutiva de pensamiento (figura sententiae), según los postulados retóricos de Cicerón, el anónimo autor de la Rhetorica ad C. Herennium, Quintiliano o Iulius Rufinianus ${ }^{29}$, distaba un tanto de su más arriesgada interpretación como tropo, en paridad estilística con formas como la metáfora, el epíteto o la metonimia; una condición esta última reconocida por la gramática de la Antiguiedad tardia, que aludiría bajo el término de homoeosis a un género ejemplar convenientemente ilustrado con pasajes procedentes de la Eneida. ${ }^{30}$ Pero esa variedad de planteamientos era, precisamente, el más cumplido precedente de una dispersión como la evidenciada por las artes medievales. Beda aludiría así a la condición de tropi que ostentaban las formas y especies de la comparación — denotada de nuevo por el término homoeosis-, y conciliaría las definiciones de las mismas aportadas por la tradición gramatical con algunos ejemplos procedentes de la Sacra Pagina. Un aspecto más de ese descubrimiento de todo un sustrato retórico-literario en el texto bíblico, que tantos autores recordarían como prueba de la necesidad -y legitimidad, de paso- del estudio propedéutico de los colores rhetorici grecolatinos por parte del orador sacro. ${ }^{31}$

27. Ioannes de Sancto Geminiano, Universum praedicabile, Praefatio, o.c., p. 2 («Pero de igual modo que en las obras de arte, así también en las costumbres y en los actos de virtud disponemos de un doble ejemplo. Pues, sin duda, en primer lugar tenemos por la fe en nuestro interior a Cristo. (...) Y este es el principal modelo de una vida perfecta. (..) Pero existe otro ejemplar exterior, la naturaleza de las cosas creadas que están fuera del alma, que es considerado en la actividad del hombre, no sólo en las obras de arte (...) sino incluso en las costumbres y en los actos de virtud (..) Pues de csas mismas obras de la naturaleza se deducen símiles y numerosísimos ejemplos útiles, relativos a nuestras costumbres»). El testimionio de San Basilio (Epistola ad Gregorium de vita solitaria) fue recogido en la célebre Polyanthea Nova de Dominicus Nanus Mirabellus, loc.cit. El pasaje de San Juan Crisóstomo (Homilía XIII), en Juan González de Critana, Sylua comparationum. Valladolid, Ioannes Godinez a Millis, s.a. [Santander, Biblioteca Municipal, sign. XVII-20], fols. 114v-115r. Para el empleo de la misma imagen en relación con la actividad intelectiva del hombre, vid. Ercilla, J., o.c., pp. 113-126. Para un tratamiento más detallado de esá identidad entre exenplunt artis y exemplun virtutis, me permito remitir a mi o.c., pp. 25-30.

28 Son palabras de Humbert de Romans y del anónimo autor del Speculum exemplonm, respectivamente. Cfr. supra nota 4.

29 Crr. Cicerón, De oratore, III, 37 (ed. de W. Friedrich, Leipzig, Teubner, 1912); Ad C. Herennium de Arte Rhetorica, IV, 48, 6 ( (ed. de F. Marx, Leipzig, Teubner, 1884); Quintiliano, Instiutio oratoria, o.c., VIII, 3, 72 y ss., y IX, 1-2; Iulius Rufinianus, De figuris sententiarum et elocutionis, 44 (en Rhetores latini minores, ed. de H. Halm, Leipzig, Teubner, 1863).

30 Homoeosis est minus notae rei per similitudinem eius quae magis nota esi demonstratio, huius species sunt tres, icon, parabole, paradigma (Donato, Ars maior, 402, en Grammatici latini, Opera, ed. de H. Keil, Leipzig, Teubner, 1857 , vol: V; «La homoeosis es la demostración de algo menos evidente a partir de su semejanza con algo más evidente. Sus especies son tres: imagen, parábola y paradigman). Y cfr.: Flavius Sosipater Charisius, Artis Grammaticae libri V, IV (vol. I, p. 277); Diomedes, Artis Grammaticae libri III (vol. I, pp. 463-464); Marius Servius Honoratus, Conmentarius in Donatum, (vol. V, p. 448); Pompeius, Commentum Artis Donati (vol. IV, p. 312).

31 Vid. Beda, Liber de schematibus et tropis (en Rhetores latini minores, o.c., pp. 607-618). 
Y seria de nuevo la reflexión sobre la parábola -retórica y evangélica a un tiempo- la piedra angular de esa convergencia sacro-profana: Rabano Mauro indicaría lo significativo de unos libros bíblicos que añadían al uso frecuente de tropos y figuras el conocimiento estricto, casi técnico, de sus nombres y especies -istorum autem troporum non solum exempla sicut omnium, sed quorundam etiam nomina in divinis libris leguntur, sicut allegoria, aenigma, parabola- y San Julián de Toledo, que había mostrado un tratamiento en extremo convencional de la elocutio, no dudaba en sustituir los ejemplos virgilianos por un curioso pasaje bíblico al propósito de la forma que nos ocupa. ${ }^{32}$ La variedad en esa consideración elocutiva de la similitudo no tenía límites: si el tratado medicval que ocupó el lugar de los textos de Prisciano y Donato en la enseñanza universitaria de la gramática, el Doctrinale de Alexander de Villadieu, también respetaba esa conciliación entre la tradición clásica y la ilustración de las formas comparativas por medio de los ejemplos cristianos, las primeras poéticas medievales ofrecían una curiosa restauración de la lectura de la similitudo como figura de pensamiento. Una recuperación tardía de las tesis retóricas favorecida sin duda por la difusión ininterrumpida de la Rhetorica ad $C$. Herennium, y que sancionaba, sin lugar a dudas, una nueva concepción de la analogía como eje y soporte de todo discurso, oratorio o poético, latino o romance:

\section{Saepius ex re \\ Dissimili similem traho. Vel cum nomine certi \\ Auctoris rem, quarn dixit, vel quam prius egit, \\ Exemplum pono. Dictos vel omitto colores \\ Et color accedit alius, collatio facta \\ Formae cum simili forma sub imagine recta. ${ }^{33}$}

Todavía en el siglo XVI, Bartolomeo Cavalcanti podía aludir a la necesaria lectura de la obra de los poetas en esa búsqueda de le fintioni piu belle - parábolas, símiles y apólogos ${ }^{34}$ _, pero la capacidad de la comparación ejemplar para el adomo del discurso, su concepción como mero arti-

32 Rabano Mauro, De institutione clericonum (en Migne, PL, vol. CVII, p. 418; «De todos estos tropos, no sólo se leen ejemplos, sino incluso sus propios nombres, como 'alegoria', 'enigma', 'parábola' »); San Julián de Toledo, Ars, XIVXVIII: Parabole (...) item in Euangelio, cum Christus de Herode dixit" «Vade, dic uulpi illi" ( LLa parábola (aparece) igual mente en el Evangelio, cuando Cristo dijo de Herodes: "Id y decio a esa raposa" "; en Ars Iuliani Toletani Episcopi. Una granática latina de la España visigoda, ed. de M. A. H. Maestre Yenes, Toledo, Instituto Provincial de Investigaciones y Estudios Toledanos, 1973, pp. 179-201). Para la relación entre el Ars de San Julián y las Etmologiae de San Isidoro, al propósito estricto que nos ocupa, puede verse mi o.c., pp. 183-184.

33 Geoffroi de Vinsauf, Poetria nova, 1254-1259, en Faral, E., Les Arts Poétiques du XII et du XIII siècle. Recherches et documents sur la technique littéraire du Moyen Age, París, Honoré Champion, 1971 ( (Con más frecuencia deduzco un símil de algo diferente. U ofrezco como ejemplo, con nombre de su autor verdadero, algo que éste dijo o hizo antaño. O prescindo de las figuras señaladas y sobreviene una nueva figura, estableciendo la comparación de una forma con otra similar, bajo una imagen razonable

»). Y vid Jean de Garlande, Exempla honestae vitae, 150 y 226-234, en Habel, E, «Die Exempla honestae vitae des Johames de Garlandia, eine lateinische Poetik des 13. Jahmundertsm, en Romanische Forschungen, XIII (1902), pp. 883. 965. Para la obra de Villa Dei, cfr. la edición incunable de Barcelona, Pedro Posa, 1493 [B.N.M. I-2480], pp. 104 y ss., que incluye los curiosos comentarios de Ludovicus de Guaschis al propósito de las formas que nos ocupan.

34 Bartolomeo Cavalcanti, Retorica, III, Venecia, Fabio \& Agostin Zoppini fratelli, 1585 [Santander, Biblioteca Menéndez Pelayo, sign. (628)], p. 122. 
ficio elocutivo, poco tiene que ver con la idea teológica de una palabra destinada al hallazgo y traducción exacta de una hermosura divina previa, ajena a toda manipulación lingüística, y sabiamente identificada con el Verbo, imago et similitudo Patris. Los ejemplos de tal concepción de la belleza, analizada con suma exactitud por H. U. von Balthasar, asoman por doquier: si, para Pedro Lombardo, «la belleza (pulcritudo) perfectísima es el Hijo, o sea, la verdad del Padre, que no. se aparta de él un ápice y es el modelo de todas las cosas», también, según San Buenaventura, «el Hijo es razón y ejemplar de todas las cosas y encierra en sí y realiza el contenido de toda belleza de una manera sumamente perfectan. Y testimonios relativamente próximos pueden hallarse desde San Agustín a Santo Tomás. ${ }^{35}$

Las criaturas, como observaba el autor del linerarium, ofrecen apenas un pálido reflejo de esa armonía ( hay muchos que aman la belleza, mas la belleza no está en las cosas exteriores, sino su efigie; la verdadera belleza es la belleza de la sabidurías) y constituyen, quizá tan sólo, motivo para la intuición sobre la potencia, sabiduría y bondad divinas: «La hermosura de las cosas, en la variedad de luces, figuras y colores que se hallan, ora en los cuerpos simples, ora en los mixtos, ora en los organizados, tales como los cuerpos celestes y minerales, piedras y metales, plantas y animales, con evidencia proclaman los tres predichos atributos ${ }^{36}$ Porque incluso el deleite que provoca la consideración de todo lo creado es ante todo metáfora y espejo de la «delectación fontal y verdadera» que sólo está en Dios, de acuerdo con esa facultad de los procesos cognoscitivos del hombre para el acceso analógico a las realidades etemas ya apuntada más arriba:

Secundum hunc modum species delectans ut speciosa, suavis et salubris insinuat, quod in illa prima specie est prima speciositas, suavitas et salubritas, in qua est summa proporcionalitas et aequalitas ad generantem; in qua est virtus, non per phantasma, sed per verttatem apprehensionis illabens, in qua est impressio salvans et sufficiens et omnem apprehendentis indigentiam expellens. Si ergo «delectatio est coinunctio convenientis cum convenientio; et solius Dei similitudo tenet rationem summe speciosi, suavis et salubris; et unitur secundum veritatem et secundum intimitatem et secundum plenitudinem replentem omnem capacitatem; manifeste videri potest, quod in solo Deofontalis et vera delectatio, et quod ad ipsam ex omnibus delectationibus manuducimur requirendam. ${ }^{37}$

35 Para los dos primeros pasajes citados, vid. Von Balthasar, H.U., o.c., II, pp, 286 y 288 respectivamente. Por lo que respecta a Santo Tomás, «todas las corrientes confluyen en el pasaje principal de su estética, en el Comentario a las Sentencias (1 d 31,2, 1): El Hijo es «bellow en Dios como species (Hilario), como perfecta imago (=aequalitas et conso nantia cum Pate: San Agustín), como poseedor de la perfecta natura Dei (Aristóteles); pero como «perfecta Palabra (o Verbo) del Padrem posee la claritas (Pseudo-Dionisio), que todo lo alumbra y en la que todo se refleja (San Alberto). En la Summa Theologica incliye Tomás esta síntesis, algo modificada, llamando al Hijo imago expressa Patris, y teniendo también en cuenta con ella la doctrina tan querida por San Buenaventura» (bid, IV, p. 358).

36 Cr. respectivamente Collationes in Hexaëmeton, coll. XX, 25, 0.c., pp. 574-575 (Multi enim sunt, qui amant pulcritudinem; pulcritudo autem non est in exterioribus, sed ipsius effigies; vera autem pulcritudo est in illa pulcritudine sapientiae) e linerarium ments in Deum, 1, 14, o.c. pp. $574-575$ (Pulcritudo autem rerum secundum varietatem luminum, figuranm et colorum in corporibus simplicibus, mixtis et etiam complexionatis, sicut in corporibus caelestibus et minera libus, sicut lapidibus et metallis, plantis et amimalibus, tria praedicta evidenter prociamat).

37 Ibíd, II, 8, pp. 582-585 ("De igual modo, la especie que deleita como hermosa, suave y saludable, da a conocer que existe la primera hermosura, suavidad y salubridad en aquella primera especie, donde hay una suma proporción e igualdad respecto al engendrador, suma virtud que se intima no por fantasmas, sino por la verdad de la aprehensión, suma impresión que sana, satisface y expele toda indigencia en el aprehensor. Por lo tanto, si la delectación es "la unión de un 
La profusión analógica de un pasaje como el anterior - un deleite humano nacido de la «unión de un conveniente con su conveniente», que es a su vez símbolo del deleite divino- no puede sino confirmar el destino trascendente de una palabra que aspira, en su desnudez retórica, a convertir en signo humano un universo ejemplar. Sentido como el necesario descubrimiento de un programa estético preexistente, el ars inveniendi exempla impuesto por la teología no era una labor sencilla ni mucho menos aleatoria para aquellos autores que, como Ramón Llull, no dudaban en tildar de fantàstics a quienes propusieran falses semblances. ${ }^{38}$ Un rigor para la letra y la voz muy distante de las tópicas normas (cautiones) que las colecciones oratorias más tardías ofrecían para un hallazgo ordenado - pero enormemente libre - de los símiles, resumidas por Ioannes Dadraeus en sus Loci communes similium et dissimilium a la altura de 1577 , y basadas en la huida de aquellas comparaciones susceptibles de una interpretación contraria a la propuesta - quae in diversum sensum tor* queri possit-, o en la selección de motivos accesibles al auditorio, de acuerdo con el ejemplo de la parábola evangélica y veterotestamentaria: huius rei exemplum dedit Christus, dederunt \& prophetae qui metaphoras \& similitudines suas ex rebus vulgatissimis ut herbis, fructibus, arboribus \& c. petere solent. A ambas, sin embargo, había de imponerse una primera cautela, bien conocida en las propias escuelas filosóficas - quae quidem vulgatissima est \& in philosophorum scholis tritissima - a decir de Dadraeus: la escasa pertinencia de aquellas semejanzas que ofrecian un paralelismo absoluto en todos sus términos. Es precisamente una reflexión como esta última -y la consiguiente denuncia de los magna absurda a los que conducía su olvido-el mayor índice de la divergencia existente entre los usos del símil literario y la práctica analógica de un autor como San Buenaventura, empeñado en la exposición minuciosa de las correspondencias entre todos los ámbitos de la realidad. Pero también es cierto que el texto de los Loci communes es muy posterior a los momentos que vieron nacer la escritura escolástica, y que su censura, más que una reflexión sobre los límites teóricos de la semejanza, era una simple muestra del rechazo que aquel estilo sutil y pormenorizado merecía en su conjunto desde los inicios del Humanismo. ${ }^{39}$

conveniente con su conveniente", si la semejanza que se engendra de sólo Dios tiene la razón de lo sumamente hermoso, sumamente suave y sumamente saludable, y se une, según la verdad, según la intimidad y según la plenitud que llena toda capacidad, se ve claramente que en sólo Dios está la delectación fontal y verdadera y que todas las delectaciones nos llevan de la mano a buscar aquéllas).

38 La expresión procede de los Proverbis de Ramon. Vid. la bibliografía citada en mi «Exempla inquirere et invenite. Fundamentos retóricos para un análisis de las formas breves lulianas», en C. Alvar y J.M. Lucia Megías (eds.), La literatura en la época de Sancho IV, Universidad de Alcalá de Henares, 1996, pp. 289-311.

39 Ioannes Dadraeus, Loci communes similium et dissimilium, Partis, Michè lulianus, 1577 [B.U.Z. H-12-153], Lectori s., s.f.: In similium usu quaedam sunt adhibendae cautiones. Prima quate quidem vilgatissima est \& in philosophorum scholis tritissima: non oportere per omnia convenive similitudines, iis ad quas conferuntur, alioqui in magna absur. da incides (...) Secunda, ne sinilitudo petant ex rebus ignotis illis quibuscum agimus, sed ex rebus ad vulgi sensum accomodatis, alioqui pratpostere docebitur. Huius rei exemplum dedit Christus, dederunt \& prophetae qui metaphoras \& similifudines suas ex rebus ulgatissimis ut ex herbis, fructibus, arboribus \&c. petere solent. Tertia regula est, ne talis assumatur similitudo quae in diversum sensum torquere possit ( $\mathrm{kEn}$ el tmpleo de los similes han de observarse algunas precauciones. La primera, conocidísima y muy frecuente en las escuelas de los filósofos, que no es oportuno que las semejanzas convengan en todo con aquellos asuntos a los que se aplican; de lo contrario caerás en grandes absurdos... La segunda, que la semejanza no se deduzca de cosas desconocidas para aquellos a quienes hablamos, sino de asuntos acomodados al modo de pensar del público; de no ser así, mal se enseñará algo. Ejemplo de esto nos dio Cristo y nos dieron los profetas, que suelen deducir sus metáforas y comparaciones de cosas muy corrientes como hierbas, frutos, átboles, etc. La ter" cera regla es no tomar una semejanza que pueda ser manipulada en sentido contrarion). 


\section{DEI EXEMPLA IN OMNIBUS}

Por lo demás, las palabras de Dadraeus - a la sazón, doctor en teología por la academia parisina - ofrecen una muy engañosa imagen sobre la confluencia teórica de todas las disciplinas en la fundamentación de la analogía, una suerte de disolución de la distancia que evidenciaban los ámbitos retóricos y filosóficos en la defensa de sus respectivos presupuestos. Pero su apelación a las philosophorum schola o la propia mención del nombre de Santo Tomás en su breve repaso a la historia del género nada tienen que ver, en efecto, con ese universo ejemplar de raigambre neoplatónica dibujado por el escolasticismo. El pasaje apela tan sólo a un uso «ilustrativo» del símil en la obra del Aquinate - D. Thomas summus \& philosophus \& theologus, nullam pene quaestionem explicat nisi adducta quadam similitudinem $-{ }^{40}$ y revela, en todo caso, la dificultad para la acotación léxica de un género tantas veces asumido desde las más diversas disciplinas y quẹ aquí hemos dado en denominar, a tenor de su origen y de su más apropiado ámbito de utilización, semejanza oratoria. El propio San Buenaventura - y tantos teólogos posteriores- abundan en ese empleo del género more rhetorico para la explicación de sus tesis, conscientes o no de su mayor adecuación a otro tipo de discurso, y a esa ausencia de límites parece aludir Ioannes Dadraeus en su recuerdo de un género cuyo empleo era tantus tamque frequens apud omnes scriptores, sell sacros, seu prophanos... quain quod frequentissimum esse potest. ${ }^{41}$ También, desde una perspectiva contraria, Alain de Lille podía servirse de un contexto indudablemente literario para ofrecer toda una reflexión sobre esa dimensión ejemplar que la teología había explorado en su lectura de la Creación, al amparo de la conocida idea del hombre como microcosmos: Ego sum illa quae ad exemplarem mundanae machinae similitudinem hominis exemplavi naturam, ut in eo velut in speculo, ipsius mundi scripta natura appareat. . $^{42}$

Cuestión bien distinta es, sin embargo, si esos modelos analógicos - al margen de la denominación que hoy pudiera otorgárseles- llegaron a hallar una conciliación real en el decurso de su historia, un momento de convergencia que armonizara su sustancial diversidad. Desde un punto de vista teórico, la obra de Ramón Llull ofrece más de un motivo para esa reflexión, dada su peculiar concepción de unos recursos oratorios voluntariamente identificados con los propios mecanimos lógicos para la fundamentación del modus essendi del universo: la voz exemplum participa en su obra de los presupuestos de ambas tradiciones, e incluso su idea de pulcritudo diluye toda distan-

40 Ibíd. («Santo Tomás, sumo filósofo y teólogo, apenas explica ninguna cuestión sin aducir alguna semejanza»).

41 Loc.cit. («Tan importante y tan frecuente entre los escritores sacros y profanos cuanto pueda llegar a serlo»). Por lo que respecta a su uso oratorio: Quod si cum populo res sit, nihil est quod seu in docendo, seu delectando, sive extollendo, sive elevando, sive consolando, potentius influat in animos auditorum (Ibid.; «Si se emplea ante el pueblo, nada incide más en los ánimos de los oyentes que el (símil), enseñando, deleitanto, ensalzando, elevando o consolando»). En esa constante presencia de símiles y metáforas - con un sentido de nuevo meramente ilustrativo- en la propia obra de San Buenaventura ha insistido M. Oromí (loc.cit.). Pero ya desde Aristóteles se había indicado la mayor adecuación del. género al discurso oratorio, fomentando un uso muy limitado del mismo en otros ámbitos, como el filosófico o dialéctico (para un tratamiento más extenso de esta última cuestión, cfr. mi o.c., pp. 67-164).

42 Cit. por L. Spitzer, o.c., p. 95 («Yo soy aquella que, a semejanza ejemplar de la máquina del mundo, ejemplifiqué la naturaleza del hombre, de modo que aparezca en él, como en un espejo, escrita la naturaleza del propio mundo»). 
cia entre la armonía cósmica y la de un discurso que tan sólo alcanza su hermosura desde el reflejo perfecto, de nuevo desnudo, de esa realidad. Pero la obra del beato mallorquín es, por tantas razones, excepcional, y el período medieval no parece haber prodigado testimonios similares de esa convergencia. ${ }^{43}$

La explicación de ese silencio mutuo, de esa aparente distorsión en la historia de la analogía no es, a pesar de todo, tan sencilla. $Y$ es cierto que tan sólo un conocimiento más eficaz de las secuencias dispersas en los sermones y vinculadas en los repertorios al uso puede ofrecer alguna conclusión válida al respecto. La preferencia oratoria por una materia ejemplar harto más sencilla que la propuesta desde la escritura escolástica no invalida la utilidad de esta última en la explicación efectiva de las verdades de la fe ante un auditorio popular. Y tampoco parece posible inferir un desconocimiento de las tesis neoplatónicas por parte de los compiladores retóricos: cuando Bartolomeo Cavalcanti, a fines del Quinientos, aconsejaba explorar le similitudine delle cose para elaborar un adecuado compendio de formas breves, no estaba pensando, obviamente, en las complejas tesis que la escolástica había difundido desde hacía tres centurias; pero quizá la idea básica de una naturaleza analógica por voluntad divina imperaba, siquiera vagamente, en su propia recomendación.

Pero es cierto que tampoco la lectura de las escasas colecciones de símiles difundidas por las prensas permite inferir un mayor alcance de esa posible conciliación. El mencionado compendio de Dadraeus, sin ir más lejos, aspiraba a ordenar, de acuerdo con un sistema de loci communes bien consolidado por esas fechas, un elenco casi infinito de secuencias ejemplares procedentes de los textos más lejanos, diluyendo cualquier distancia entre todos los modelos posibles del género. En su pertinente index auctoritatum falta el nombre de San Buenaventura, pero no así los de Dionisio, Agustín, Anselmo, Alberto Magno o Ricardo y Hugo de San Víctor, tan gratos a la génesis y el desarrollo de la similitudo teológica. A pesar de todo ello, la obra apenas ofrece unas cuantas muestras de esa ambiciosa lectura ejemplar de la Creación, reubicadas de acuerdo con su proyección temática y no desde luego en virtud de aquel sistema complejo de correspondencias cuya pertinencia, por lo demás, había quedado muy matizada desde el propio prefacio del escrito. No deja de resultar curioso que la colección ofrezca incluso una serie encabezada con un epígrafe de evidentes resonancias escolásticas: Dei exempla in omnibus. Pero lejos

43 Me ocupo del caso luliano en «Falses semblances. Ejemplarismo divino y literatura ejemplar a la luz de Ramón Llull», en Actas del VIII Congreso de la A.H.L.M. (en prensa).

44 El capítulo (o.c., fols. 139-140) ofrece en su mayoría semejanzas literarias. Tan sólo una de esas secuencias se relaciona, muy indirectamente, con ese esquema teológico que aquí nos ha ocupado: Quemadmodum mundi partes sunt coelum, aqua, terra \& aer, eodem modo membra Dei, vita, mortalitas, necessitas, providentia, natura, anima, mens, horumque omnium participatio, ipsum bonum: neque fit aliquid usquam neque est factum, ubi Deus ipse non adsit («Del mismo modo que el cielo, el agua, Ia tierra y el aire son partes del mundo, son miembros de Dios la vida, la mortalidad, la necesidad, la providencia, la naturaleza, el alma, la mente, la participación de todas estas cosas, el mismo bien. Y nada se hace jamás ni ha sido hecho, en lo que el propio Dios no esté presente»). La secuencia procede, de hecho, de Trimegisto. La obra incluye un capítulo con el título de Exemplum et similitudo, pero tampoco aquí aparece la huella de ese ejemplarismo teológico. La mayor parte de sus secuencias aluden al sentido y función dé la parábola. 
de testimoniar una definitiva vinculación entre los dos ámbitos de la analogía que nos ocupan, la lectura de las secuencias allí integradas - sin apenas huellas de ese complejo edificio bonaventuriano- y la propia presencia del tema como un tópico más - locus communis - en un conjunto casi infinito, son la principal prueba de la escasa impregnación que el escrito muestra de aquel riguroso ejemplarismo medieval. Un modo este último de entender la similitudo que no parece siquiera constituir un episodio mayor en la amplia historia del género vislumbrada por Ioannes Dadraeus. ${ }^{44}$

José Aragüés Aldaz Departamento de Filología Española

Universidad de Zaragoza 50009 Zaragoza 